\title{
First report of potato wilt caused by Plectosphaerella cucumerina in Pakistan
}

\author{
Muhammad Waqar Alam ${ }^{1}\left[\right.$ D $\cdot$ Arif Malik $^{1} \cdot$ Abdul Rehman $^{2} \cdot$ Mubeen Sarwar $^{1} \cdot$ Saira Mehboob $^{3}$
}

Received: 21 November 2020 / Accepted: 22 January 2021 / Published online: 27 January 2021

(c) Società Italiana di Patologia Vegetale (S.I.Pa.V.) 2021

Keywords Solanum tuberosum $\cdot$ Disease severity $\cdot$ Identification $\cdot$ Pathogenicity

Potato (Solanum tuberosum L.) is one of the most consumed and fastest growing staple food crop of Pakistan. Potato cultivation is mainly focused in Punjab, where currently over $95 \%$ of the potato production originates (Abdul and Zahir 2018). In November 2019, wilt symptoms were observed in multiple fields of potato located in Faisalabad ( $31^{\circ} 25^{\prime} 15.7620^{\prime \prime} \mathrm{N}$; $73^{\circ} 5^{\prime} 21.4584^{\prime \prime}$ E) - district of Punjab Province, Pakistan. Symptoms included water-soaked rot on stems and dark brown to black vascular discoloration of feeder roots. Under severe conditions, the whole plant became wilted. The incidence was $30-50 \%$ in the visited fields. Small pieces of feeder roots were excised, surface disinfected with $0.5 \%$ sodium hypochlorite for $2 \mathrm{~min}$, rinsed with sterile distilled water, placed on potato dextrose agar (PDA), and incubated at $25^{\circ} \mathrm{C}$. A fungus was consistently isolated by picking hyphal tips from the colony edge to a fresh PDA plate. Colonies on PDA were white-cream colored that turned pink gradually, slimy, with hyaline, sparse aerial mycelium. Conidia were hyaline, smooth, thin walled, $0-1$ septate, elliptical to ovoid, and born on phialides, measuring 4.2 to $9.6 \times 1.5$ to $4.5 \mu \mathrm{m}$. The conidiophores were non-branched and conidiogenous cells were monophialidic and hyaline. All the morphological characteristics resembled to Plectosphaerella cucumerina (Lindf.) W. Gams (Carlucci et al. 2012). To confirm the identification based on morphological features, genomic DNA of a representative isolate (PDL 2023) was extracted and the internal transcribed spacer (ITS) region was amplified using ITS1/ITS4 primers and sequenced (White et al. 1990). BLAST

Muhammad Waqar Alam

waqar.alam@imbb.uol.edu.pk

1 Institute of Molecular Biology and Biotechnology, The University of Lahore, Lahore, Pakistan

2 Department of Plant Pathology, University of Agriculture, Faisalabad 38040, Pakistan

3 Plant Pathology Research Institute, Ayub Agricultural Research Institute Faisalabad, Punjab 38000, Pakistan analysis of the resulting sequence (GenBank accession No. MW281733) confirmed the identity of the fungus, showing $99 \%$ to $100 \%$ homology to the multiple sequences of $P$. cucumerina. To determine pathogenicity, ten potato tubers were planted into four pots with 2 tubers in each pot. The pots were maintained under temperature $25{ }^{\circ} \mathrm{C}$ and $50 \%$ RH. Fifteen days later, three 6- to 8-cm-deep triangular holes were dug with a fruit knife in each pot. The potato seedlings were inoculated by pouring $50 \mathrm{ml}$ of the conidia suspension $\left(1 \times 10^{5}\right.$ conidia/ml $)$ into each hole. As a control, the roots of ten plants were inoculated with sterilized water only. After 10 days, all the inoculated plants except controls, showed symptoms resembled to natural ones. To complete the Koch's postulates, reisolation from inoculated plants was done and same fungus was consistently isolated. To our knowledge, this is the first report of potato wilt caused by $P$. cucumerina in Pakistan.

\section{Declarations}

Conflicts of interest The authors declared no conflict of interest.

\section{References}

Abdul M, Zahir M (2018) Potato Production in Pakistan: Challenges and Prospective management strategies- A review. Pak J Bot 50:2077-2084

Carlucci A, Raimondo ML, Santos J, Phillips AJL (2012) Plectosphaerella species associated with root and collar rots of horticultural crops in southern Italy. Persoonia 28:34-48

White TJ, Bruns T, Lee S, Taylor J (1990) Amplification and direct sequencing of fungal ribosomal genes for phylogenetics. In: Innis M.A., Gelfand D.H., Shinsky J., White T.J. (eds). PCR Protocols. A Guide to Methods and Applications, pp. 315-322. Academic Press, San Diego,CA, USA.

Publisher's Note Springer Nature remains neutral with regard to jurisdictional claims in published maps and institutional affiliations. 